\title{
HIV vaccine trials planned for Africa
}

Speaking at the XIIIth World AIDS Conference in Durban last month, Oxford University immunologist, Andrew McMichael announced the approval for human testing of a DNA/modified vaccinia virus prime boost HIV vaccine he is developing in conjunction with the University of Nairobi in Kenya.

A Phase I safety trial of the gag DNA component of the vaccine will begin this month with 18 volunteers in Oxford-one of which is the Member of Parliament for Oxford, Evan Harris. Testing of the vaccinia boost unit will start next month, combi-
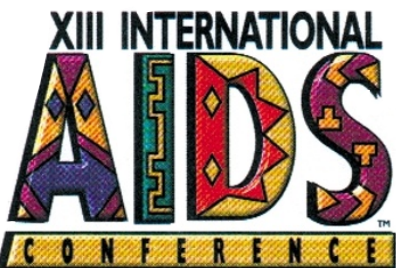
DURBAN • SOUTHAFRICA • 9.14 JULY 2000 of the South African Medical Research Council, William Makgoba, told Nature Medicine that SAAVI aims to complete Phase III trials by 2005. Development of the VEE vaccine is supported by IAVI and by North Carolina based, Alphavax (Nature Med. 5, 1220; 1999).

The effort to develop a South African vaccine will be aided by R100 million (US\$ 14.7 million) over a fiveyear period awarded to the MRC last month by the US National Institutes of Health. R10 million of the funding will be used to establish a vaccine trial unit and R6 million will go to the nation testing isslated for October, and trials in Kenya are expected to begin by the end of the year. The trial is supported by the International AIDS Vaccine Initiative (IAVI).

Meanwhile, South Africa's effort to de velop its own HIV vaccine will be put to the test early next year. The South African AIDS Vaccine Initiative (SAAVI) has announced that it will begin human trials of its Venezuelan equine encephalitis (VEE) virus vaccine in Kwazulu-Natal in January 2001, provided permission is granted by the South African Medicines Control Council (MCC) in October. The president
The challenges that developing countries face in trying to produce their own HIV vaccine were discussed at the Durban AIDS meeting. Roy Widdus of the independent Swiss foundation, Global Forum for Health Research, a principal author of IAVI's blueprint, "AIDS vaccines for the World: Preparing Now to Assure Access" admits that there are pitifully few institutions capable of producing quality vaccines outside developed nations but calls for their involvement to be maintained because of the high volume of vaccine that might be needed to immunize against HIV worldwide.

Helen Rees, chair of the MCC, discussed the worldwide attention that the first trial of a home-grown vaccine in her country will attract: "AIDS is sensitive terrain. Vaccine testing will involve trials on poor black people, run by white organizers. The clinical schedule must be solid and defensible." Rees also revealed that her agency has been in discussions with the US Food and Drug Administration via the head of the White House AIDS unit, Sandra Thurman, regarding special regulations to facilitate the development of an HIV vaccine

The first trial of an HIV vaccine began in Africa last year. The HIVNET007 study is sponsored by the US National Institutes of Health and is testing a canarypox vaccine in 40 HIV negative Ugandans.

Karen Birmingham, Durban

\section{NIAID funds new groups to develop HIV vaccines}

The US National Institute of Allergy and Infectious Diseases Division of Acquired Immunodeficiency Syndrome (NIAID/DAIDS) has announced the funding of $\$ 70$ million in contracts over the next five years for the development of an HIV vaccine. The contracts come under a new program created last year, HIV Vaccine Design and Devel opment Teams (HVDDT), the goal of which is to fund academics working alongside industry to move a vaccine concept more rapidly from the laboratory into GMP pilot manufacturing and early clinical trials.

"With AIDS vaccines, we have to be product-oriented," says Stuart Shapiro, the HVDDT project officer. So, he notes, these contracts differ from other NIAID AIDS-related contracts in that they are broad-extending from synthesis of test molecules, immunogenicity studies, GMP manufacturing and process devel- opment, FDA filings and clinical trialsand are milestone driven.

The four projects funded are for prime-boost vaccine candidates. All prime with DNA, including some HIV genes; two have protein boosts, whereas the other two have live vector boosts.

California-based Chiron Corporation, which is receiving $\$ 24.3$ million, will de velop their clade $B$ and clade $C$ vaccine candidates entirely in-house, according to Shapiro. The other three, however, are composed of industry-university teams. Maryland-based Advanced BioScience Laboratories, which will receive $\$ 15.5 \mathrm{mil}$ lion, will be working with Shan Lu at the University of Massachusetts Medical School. Wyeth Lederle Vaccines of New York, will receive \$14.1 million. Their university partners-David Weiner at the University of Pennsylvania and Hua-Xin Liao at Duke University-will be conduct- ing basic research and development on the DNA primer and the peptide boost, respectively.

The most diverse group is an Australian consortium led by David Cooper, director of the National Centre in HIV Epidemiology and Clinical Research, University of $\mathrm{New}$ South Wales (UNSW). Collaborators include the University of Melbourne; the Australian National University in Canberra; the University of Newcastle; the National Centre in HIV Social Research at UNSW; the Australian Federation of AIDS Organisations; the CSIRO Division of Animal Health, a government entity in Geelong; a commercial partner; and a contract research organization, International Drug Technologies, also of Melbourne. The group's tech nology is licensed to Virax Holdings and the consortium has been awarded $\$ 16.1$ million.

Myrna E. Watanabe, Connecticut 